\title{
Molecular analysis of patients of Sardinian descent with Crigler-Najjar syndrome type I
}

\author{
M C Rosatelli, A Meloni, V Faà, L Saba, G Crisponi, M G Clemente, G Meloni, \\ $M$ T Piga, A Cao
}

\begin{abstract}
This study reports the molecular characterisation of the bilirubin UDPglucuronosyl-transferase gene (UGT1) in a group of patients of Sardinian descent with Crigler-Najjar syndrome type I and their relatives.

Sequence analysis of both UGT1A exon 1 and common exons 2-5 was performed in all patients, leading to the detection of $\Delta F 170$ and a novel mutation (470ins T), both residing in UGT1A exon 1 . All but two heterozygotes for the $\Delta F 170$ mutation showed normal serum bilirubin levels. These two subjects were also heterozygous for the sequence variation A(TA), TAA in the promoter region of the UGT1A gene. (F Med Genet 1997;34:122-125)
\end{abstract}

Keywords: $\mathrm{CN} 1$; mutation analysis; Gilbert syndrome.

Istituto di Clinica e Biologia dell'Età Evolutiva, Università degli Studi di Cagliari, Via Jenner s/n, 09121 Cagliari, Sardinia, Italy

M C Rosatelli

L Saba

M G Clemente

A Cao

Istituto di Ricerca per le Talassemie e Anemie Mediterranee CNR Cagliari, Cagliari, Sardinia, Italy

A Meloni

$\mathrm{V}$ Faà

Istituto di

Puericultura, Università degli Studi di Cagliari, Cagliari, Sardinia, Italy

G Crisponi

\section{Clinica Pediatrica e}

Neonatologica,

Università degli Studi

di Sassari, Sassari,

Sardinia, Italy

G Meloni

M T Piga

Correspondence to: Dr Rosatelli.

Received 7 June 1996 Revised version accepted for publication

4 September 1996
Crigler-Naijar (CN) syndrome is an inborn error of metabolism, which is characterised by severe unconjugated hyperbilirubinaemia ${ }^{1}$ resulting from defective activity of the hepatic enzyme bilirubin UDP-glucuronosyltransferase (UGT). CN syndrome has been classified into two types according to the degree of hyperbilirubinaemia and response to phenobarbital administration. ${ }^{2}$ In type I, the level of unconjugated bilirubin in serum is usually above $340 \mu \mathrm{mol} / 1$ and phenobarbital treatment does not reduce it significantly. Type II patients have serum bilirubin levels in the $120-340 \mu \mathrm{mol} / 1$ range and respond to phenobarbital treatment by a decrease of at least $25 \%$ of bilirubin levels. CN-I is inherited as an autosomal recessive disorder, whereas for type II both autosomal recessive and dominant inheritance with variable penetrance have been reported.

The recent identification of a large gene locus termed UGT1, which encodes a family of UDP-glucuronosyl-transferase (UGT1AUGT1M) including the two bilirubin transferase isoforms, has provided the tools for studying hereditary/unconjugated hyperbilirubinaemia at the molecular level. ${ }^{34}$ The complex UGT1A-UGT1M codes for at least two bilirubin transferase, three bilirubin-like, and eight phenol-transferase isozymes. ${ }^{5}$ In the 5 ' region of the locus, a minimum of 13 different exons 1 are located, each with an upstream specific promoter, while the 3 ' region contains four common exons. Each exon 1 encodes the amino-terminus of a specific transferase and the common exons (2-5) encode the common carboxyl-terminus of each isoform. The product of the UGT1A gene is the predominant bilirubin isoform in liver, while the product of the UGT1D gene is the less abundant and phenobarbital responsive bilirubin transferase isoenzyme.

Mutation analysis in patients with CriglerNajiar type I has detected deletions, nonsense and missense mutations most commonly in the common exons and occasionally in the unique specific exon of the UGT1A unit. This finding of mutations in the specific exon 1, together with the transfection experiments in COS cells, indicates that the UGT1A unit codes for the only relevant isoform in bilirubin glucuronidation. ${ }^{6}$ In the few patients with $\mathrm{CN}$-II analysed molecularly to date, missense mutations in the specific exon 1 of the UGT1A unit, or in common exons, have been detected, in some cases associated with missense mutations of unique exon 1 of the UGT1D gene. ${ }^{7-9}$

More recently, patients with Gilbert syndrome, the mildest of the inherited hyperbilirubinaemias, were found to be either heterozygous for missense mutations in the specific exon 1 of UGT1A or in the common exon 4 or $5,{ }^{10}{ }^{11}$ or homozygous for an extra TA dinucleotide in the TATA sequence of the promoter region of UGT1A (A(TA) TAA instead of the normal $\left.\mathrm{A}(\mathrm{TA}){ }_{6} \mathrm{TAA}\right) .^{12-14}$

Here, we describe the results of the molecular characterisation of the UDP-glucuronosyltransferase gene in a group of patients of Sardinian descent with Crigler-Najjar syndrome type I and their relatives.

\section{Patients}

We have examined five patients with severe unconjugated hyperbilirubinaemia belonging to four families of Sardinian descent. All patients, who were born to nonconsanguineous parents, had persistent nonhaemolytic hyperbilirubinaemia (level $>250$ $\mu \mathrm{mol} / 1$ ). One patient (PE) required an exchange transfusion during the neonatal period because of a sudden increase of bilirubin levels $(547 \mu \mathrm{mol} / \mathrm{l})$. An exchange transfusion was carried out in infancy in patient PL, whose bilirubin levels increased up to $684 \mu \mathrm{mol} / 1$ with associated signs of neurological dysfunction (slurring of speach, drooling, reduced contro of truncal tone, abnormality of fine hand movements, and moderate ataxia). This patien also had a mild form of dyskinetic central palsy with intelligence in the low-normal range. The bilirubin levels in all patients were unresponsive to phenobarbital administration. Limited 
Table 1 Relevant clinical features of Crigler-Najjar type I patients

\begin{tabular}{|c|c|c|c|c|c|c|c|c|}
\hline \multirow[b]{2}{*}{ Patients } & \multirow[b]{2}{*}{ Age (y) } & \multirow[b]{2}{*}{ Genotype } & \multicolumn{2}{|c|}{ Max bilirubin levels } & \multicolumn{2}{|c|}{ Exchange transfusions } & \multirow[b]{2}{*}{$\begin{array}{l}\text { Neurological } \\
\text { dysfunction }\end{array}$} & \multirow[b]{2}{*}{$\begin{array}{l}\text { Liver } \\
\text { transplantation }\end{array}$} \\
\hline & & & $\begin{array}{l}\text { Neonatal } \\
\text { period }\end{array}$ & $\begin{array}{l}\text { Infancy/ } \\
\text { childhood }\end{array}$ & $\begin{array}{l}\text { Neonatal } \\
\text { period }\end{array}$ & $\begin{array}{l}\text { Infancy/ } \\
\text { childhood }\end{array}$ & & \\
\hline CR & 13 & $\Delta \mathrm{F} 170 / \Delta \mathrm{F} 170$ & 273 & & None & None & Absent & Yes \\
\hline PL & 8 & $\Delta \mathrm{F} 170 / \Delta \mathrm{F} 170$ & 342 & 684 & None & One & Present & Yes \\
\hline $\mathrm{PE}^{\star}$ & 16 & $\Delta \mathrm{F} 170 / 470$ ins $\mathrm{T}$ & 547 & & One & None & Present & No \\
\hline $\mathrm{PA}^{\star}$ & 4 & $\Delta \mathrm{F} 170 / 470$ ins $T$ & 256 & 291 & None & None & Absent & No \\
\hline PEd & 1 & $\Delta \mathrm{F} 170 / \Delta \mathrm{F} 170$ & 308 & - & None & - & Absent & No \\
\hline
\end{tabular}

«Sibs.

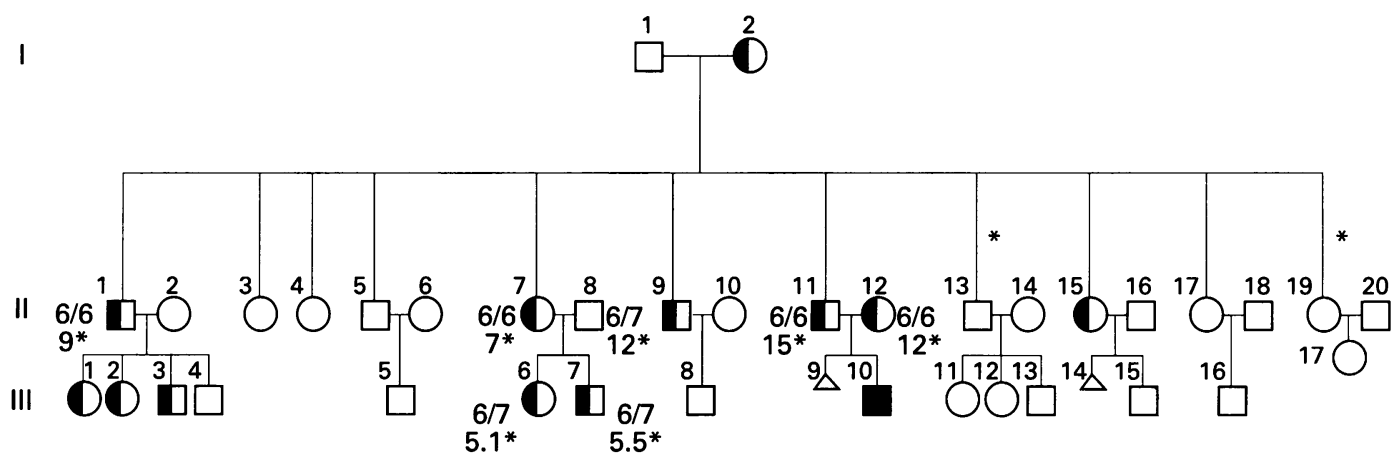

Figure 1 Family pedigree of PEd. II.6 and II. 7 have Gilbert syndrome. III. 10 is the proband homozygous for the $\Delta F 170$ mutation. 6/6 genotype $=A(T A)_{6} T A A / A(T A)_{6} T A A .6 / 7$ genotype $=A(T A)_{6} T A A / A(T A), T A A .{ }^{*}=S T B$ concentration $(\mu \mathrm{mol} / \mathrm{l}) .{ }^{*}$ above families $=$ members not tested.

reduction of the serum bilirubin levels was observed with phototherapy, which was used continuously in all the patients. Patient PL also required sporadic plasmapheresis to reduce the toxic high bilirubin levels. Liver biopsy was carried out in patient PL, in whom hepatic UDP glucuronosyl-transferase was absent. In two patients (CR and PL), aged 12 and $61 / 2$ years respectively, orthotopic liver transplantation was carried out. After transplantation, the patients' serum bilirubin levels rapidly returned to normal. These data are summarised in table 1 . In six relatives of one of the patients investigated (PEd), who were found to be heterozygous for a mutation in the UDP glucuronosyl-transferase gene, we carried out serum total bilirubin determination (STB). The results were normal in all but two, who had been previously diagnosed as affected by Gilbert syndrome (fig 1).

\section{Mutation analysis}

Sequence analysis of both the specific exon 1 of UGT1A and the common exons 2-5 in all the five patients showed two mutations in exon 1, the previously described deletion of the phenylalanine codon (TTC) at position $170(\Delta \mathrm{F} 170)$ of UGT1A and a novel mutation, the insertion of a $\mathrm{T}$ at codon 158-159 (470ins $\mathrm{T}$ ), which results in a frameshift and in the production of a downstream stop codon (TGA) at position 182 (fig 2). Of these patients, three unrelated ones were homozygotes for $\Delta \mathrm{F} 170$ and two sibs were compound heterozygotes for $\Delta \mathrm{F} 170$ and 470ins T. Of the 10 chromosomes carrying a defective UGT1A gene, eight thus contained the $\Delta \mathrm{F} 170$ mutation.

The $\Delta \mathrm{F} 170$ mutation may be easily detected by electrophoretic separation of a $401 \mathrm{bp}$ DNA fragment containing the mutation on a $2 \mathrm{~mol} / \mathrm{l}$ urea, $6 \%$ polyacrylamide gel. The $401 \mathrm{bp}$ fragment was amplified with forward primer

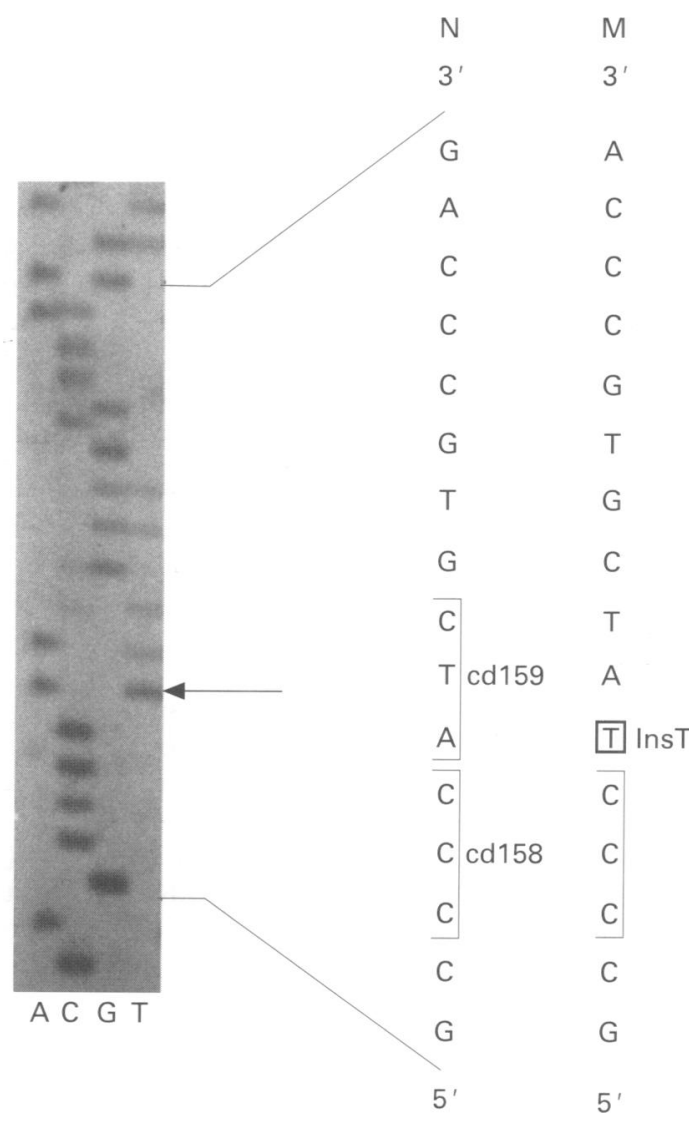

Figure 2 Sequence analysis of UGT1A exon 1 gene for the identification of the 470insT mutation. The arrow indicates the localisation of the mutation. $N$ and $M$ show the normal and mutant sequences respectively.

AGCTCATGGCCTCCCT and reverse primer GATGGGCCTAGGGTAAT for 25 PCR cycles at $94^{\circ} \mathrm{C}$ for 30 seconds, $55^{\circ} \mathrm{C}$ for 30 seconds, $72^{\circ} \mathrm{C}$ for one minute in a Perkin-Elmer Cetus Thermal Cycler 9600 (fig 3 ). This procedure was used for screening the relatives of patient PEd. Six of them, hetero- 

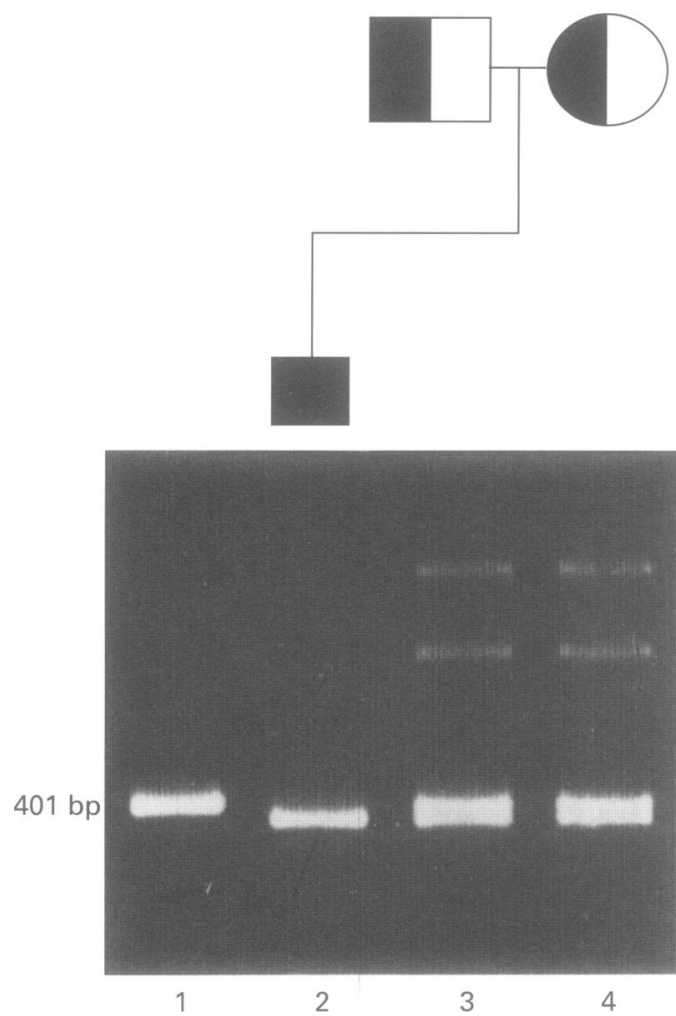

Figure 3 Polyacrylamide gel electrophoresis of a $401 \mathrm{bp}$ $P C R$ product containing part of UGT1A exon 1. Lane 1 normal subject, lane 2 proband homozygous for $\triangle F 170$ mutation, lanes 3 and 4 parents heterozygous for the $\triangle F 170$ mutation.

zygous for the $\Delta \mathrm{F} 170$ mutation, were investigated for the $A(T A)_{7}$ TAA nt variation. Only the two subjects with increased STB concentration in this group showed heterozygosity for $\mathrm{A}(\mathrm{TA})_{7} \mathrm{TAA}$, the others being homozygous for A(TA) ${ }_{6}$ TAA.

\section{Discussion}

In this study, we have characterised the molecular defect in the bilirubin UDPglucuronosyl transferase gene in five patients affected by Crigler-Najjar syndrome type I belonging to four families of Sardinian origin. We found three patients homozygous for a previously described mutation, the deletion of the phenylalanine codon at position $170(\Delta \mathrm{F} 170)$ of exon 1 of UGT1A, and two patients from the same family compound heterozygous for $\Delta \mathrm{F} 170$ and a novel mutation consisting of the insertion of a $T$ at codon 158-159 (470ins $T$ ) of exon 1 of UGT1A.

The $\Delta \mathrm{F} 170$ mutation has been previously described in a single patient of caucasian orgin. ${ }^{15}$ This mutation abolishes a conserved diphenylalanine at this position and results in the production of one third level of mRNA and presumably mutant protein as compared to the wild type gene. Furthermore, the mutant protein has no enzymatic activity at low $\mathrm{pH}$ (6.4), which is the optimum $\mathrm{pH}$ for bilirubin glucuronidation.

The 470ins $T$ mutation results in a frameshift and downstream stop codon, thus probably leading to absent protein product or to the production of a shortened functionless protein. Both mutations detected in this study reside in the specific exon 1 of UGT1A. This finding is consistent with the notion that UGT1A codes for the only relevant enzymatic isoform in bilirubin glucuronidation.

It is interesting to note that seven of eight mutant alleles from unrelated patients of Sardinian ancestry carry the $\Delta \mathrm{F} 170$ mutation. This may indicate that Crigler-Najiar syndrome type I in Sardinia is prevalent because of a founder effect. A similar effect has been previously detected for Crigler-Najjar syndrome type I in France, Portugal, Turkey, and Tunisia. ${ }^{16}$

In six heterozygotes, all belonging to the same family, STB levels and promoter sequence variation were studied. Four of these have normal STB levels and absence of the promoter variation $\mathrm{A}(\mathrm{TA})_{7}$ TAA. Normal STB concentration has to date been reported in subjects heterozygous for mutations that, most likely, cause absence of protein product or production of a shortened functionless protein. Tetramers are thus assembled only from the normal subunits, probably resulting in 50\% normal activity, which may be sufficient for bilirubin metabolism in normal conditions. This could be a reason for the normal STB values shown by these subjects. Two of the $\Delta \mathrm{F} 170$ heterozygotes examined showed high STB levels $(>40 \mu \mathrm{mol} / \mathrm{l})$ and the presence of the sequence variation A(TA) 7 TAA in the heterozygous state. The sequence variation, although found in the heterozygous state, could explain the mild increase of STB concentration in these subjects. Recently it has been reported that a consistent decrease of the enzymatic activity of the UGT1A gene may also occur in those patients with Gilbert syndrome who are homozygous for the variant $\mathrm{A}(\mathrm{TA})_{7} \mathrm{TAA}$ promoter. ${ }^{12}$ The transfection of a construct containing the A(TA) 7 TAA promoter linked upstream to the firefly luciferase gene in a hepatic cell line led to a reduced luciferase expression, that is, 18 to $32 \%$ of that recorded in the presence of the normal TATA sequence motif (A(TA) ${ }_{6}$ TAA).

Further molecular analysis and mutationphenotype correlation of patients with CN-I, $\mathrm{CN}-\mathrm{II}$, and Gilbert syndrome are needed to have a clear picture of the molecular pathogenesis of these inherited hyperbilirubinaemias.

This work was supported by grants from Assessorato Igiene e Sanità Regione Sardegna LR no 1130.04 .90 , National Research Council (CNR) targeted project "Prevention and Control Diseases Factors" (FATMA) contract no 95.00782.PF41, and finanziamenti Università Studi Cagliari per la ricerca scientifica: quota $60 \% \mathrm{MCR}$.

1 Crigler JF, Najiar VA. Congenital familial non hemolytic jaundice with kernicterus. Pediatrics 1952;10:169-80.

Arias IM. Chronic unconjugated hyperbilirubinemia without overt signs of hemolysis in adolescents and adults. $f$ out overt signs of hemolysis in

3 Ritter JK, Crawford JM, Owens IS. Cloning of two human liver bilirubin UDP-glucuronosyl-transferase cDNAs with expression in COS-1 cells. F Biol Chem 1991;266:1043-7.

4 Ritter JK, Chen F, Sheen YY, et al. A novel complex locus UGT1 encodes human bilirubin, phenol, and other UDP glucuronosyltransferase isoenzymes with identical carboxy termini. F Biol Chem 1992;267:3257-61.

5 Ciotti M, Yeatman MT, Sokol RJ, Owens IS. Altered coding for a strictly conserved di-glycine in the major bilirubin UDP-glucuronosyltransferase of a Crigler-Najjar type patient. F Biol Chem 1995;270:3284-91

6 Bosma PJ, Seppen J, Goldhoorn B, et al. Bilirubin UDP-glucuronosyltransferase 1 is the only relevant bi- 
lirubin glucuronidating isoform in man. $\mathcal{F}$ Biol Chem 1994 269:17960-4

7 Aono S, Yamada Y, Keino $\mathrm{H}$, et al. Identification of defect in genes for bilirubin UDP-glucuronosyl-transferase in patient with Crigler-Najjar syndrome type II. Biochem Biophys Res Commun 1993;197:1239-44.

8 Moghrabi N, Clarke DJ, Boxer M, Burchell B. Identification of an A-to-G missense mutation in exon 2 of the UGT1 gene complex that causes Crigler-Najiar syndrome type 2. Genomics 1993;18:171-3.

9 Bosma PJ, Goldhoorn B, Oude Elferink RPJ, Sinaasappel M, Oostra BA, Jansen PLM. A mutation in bilirubin uridine 5'-diphosphate-glucuronosyltransferase isoform 1 causing Crigler-Najjar syndrome type II. Gastroenterology 1993; ing Crigler-N

10 Aono S, Adachi Y, Uyama E, et al. Analysis of genes for bilirubin UDP-glucuronosyltransferase in Gilbert's syndrome. Lancet 1995;345:958-9.

11 Koiwai O, Nishizawa M, Hasada $\mathrm{K}$, et al. Gilbert's syndrome is caused by a heterozygous missense mutation in the gene for bilirubin UDP-glucuronosyltransferase. Hum Mol Genet 1995;4:1183-6.

12 Bosma PJ, Chowdhury JR, Bakker C, et al. The genetic basis of the reduced expression of bilirubin UDPglucuronosyltransferase 1 in Gilbert's syndrome. $N$ Engl $\mathcal{F}$ Med 1995;333:1171-5.

13 Monaghan G, Ryan M, Seddon R, Hume R, Burchell B. Genetic variation in bilirubin UDP-glucuronosyltransferase gene promoter and Gilbert's syndrome. Lancet 1996;347: gene prom

14 Sato H, Adachi Y, Koiwai O. The genetic basis of Gilbert's syndrome. Lancet 1996;347:557-8.

15 Ritter JK, Yeatman MT, Kaiser C, Gridelli B, Owens IS. A phenylalanine codon deletion at the UGT1 gene complex locus of a Crigler-Najiar type I patient generates a $\mathrm{pH}$-sensitive bilirubin UDP-glucuronosyltransferase. $\mathcal{F}$ Biol Chem 1993;268:23572-9.

16 Labrune P, Myara A, Hadchouel M, et al. Genetic heterogeneity of Crigler-Najiar syndrome type 1: a study of 14 cases. Hum Genet 1994;94:693-7. 